\title{
Estimating Implied Valuation Parameters: Extension and Application to Ground Lease Rentals*
}

\author{
Glenn Boyle \\ NZ Institute for the Study of Competition and Regulation \\ Victoria University of Wellington \\ Graeme Guthrie \\ School of Economics and Finance \\ Victoria University of Wellington \\ Neil Quigley \\ School of Economics and Finance \\ Victoria University of Wellington
}

September 8, 2008

\footnotetext{
${ }^{*}$ For valuable research assistance, we are very grateful to Kevin Counsell. We have also benefited from discussions on this topic with Robert Cameron, Lew Evans, Jack Hodder and Martin Lally, and from helpful comments provided by session participants at the 2008 New Zealand Finance Colloquium, but any remaining errors and ambiguities are solely our responsibility.
} 


\title{
Estimating Implied Valuation Parameters: Extension and Application to Ground Lease Rentals
}

\begin{abstract}
A problem that often arises in applied finance is one where decision-makers need to choose a value for some parameter that will affect the cash flows between two parties, such as a rental rate or an exercise price. Because the values of the cash flows also depend on various unobservable parameters, identifying the value of the policy parameter that achieves the desired allocation between the parties is no simple task, often resulting in disputes and the invocation of ad-hoc approaches. We show how this problem can be solved using an extension of the well-known 'implied volatility' technique from option pricing, and apply it to the determination of equilibrium rental rates on ground leases of commercial land.
\end{abstract}

JEL Classification code: G12, R33.

Keywords: valuation, implied parameters, leasing, land, rental rate. 


\section{Estimating Implied Valuation Parameters: Extension and Application to Ground Lease Rentals}

\section{Introduction}

The general class of problems that we consider in this paper arise when decision-makers need to choose a value for some parameter that will affect the cash flows between two parties. For example, this parameter could be the annual rental on a piece of leased equipment or land. It might be the choice of exercise price for stock options to be issued to company executives. Or it could be the level of a price cap imposed on a regulated firm.

A typical approach in such situations is to choose the level of this parameter so that the market value of the cash flows takes some specified value. For example, often it will be set with the intention of ensuring one party to the transaction 'breaks even' - that is, the market value of their cash flow stream is equal to some measure of the cost that they face to enter into the transaction. This approach requires a mathematical model that predicts how the market value of the cash flow stream is related to the level of the policy parameter. We write this model in the form

$$
V=F(x, y, z)
$$

where $V$ is the predicted market value of the cash flow stream, $x$ is the policy parameter, $y$ is a collection of observable exogenous parameters, $z$ is a collection of unobservable exogenous parameters, and their mathematical relationship is encapsulated in the function $F$. For example, in the rent-setting problem, $x$ is the annual rental on the asset being leased, $y$ includes parameters such as the length of the lease and the frequency of rent payments and revisions, while $z$ includes parameters such as the expected growth in asset value and the discount rate appropriate to the risk of the asset. In the case of executive stock options, $x$ is the exercise price, $y$ includes the current stock price, and $z$ includes the volatility of the stock price.

If we know the values of $y$ and $z$, then the policy parameter can be set at a level such that the market value of the cash flow stream equals some exogenously-specified target level $B$. For example, in the rent-setting problem $B$ could be set equal to the market value of otherwise identical freehold land. In the case of executive stock options, $B$ will reflect the employer's assessment of the optimal tradeoff between risk and incentives. Thus, given our model (1) relating the level of the policy parameter and the market value of the cash flow stream, the policy parameter $x^{*}$ is defined in such a way that

$$
B=F\left(x^{*}, y, z\right)
$$

However, in practice we do not know the value of the unobservable exogenous parameters; these have to be estimated. The value of the policy parameter is then set so that the estimated market 
value of the cash flow stream equals $B$. That is, the achievable policy parameter $\hat{x}^{*}$ is defined by

$$
B=F\left(\hat{x}^{*}, y, \hat{z}\right)
$$

where $\hat{z}$ is the collection of estimates of the unobservable exogenous parameters.

Apart from the construction of $F$, the key step in this process is estimation of the unobservable exogenous parameters $z$. In order to achieve the desired split of cash flows between the parties, the components of $z$ must be estimated as accurately as possible, which begs the question of how this can best be achieved. One possible approach is to utilize additional theoretical models that describe the determination of the unknown parameters, and then to estimate the inputs to these models using historical data. That is, $\hat{z}$ is estimated outside the model given by equation (1). However, doing so introduces a new problem - the restrictions imposed by these additional models may be inconsistent with those of the original model, thus leading to policy choices that inadvertently combine 'apples and oranges' in an ad-hoc manner. Moreover, when there are several unobserved parameters, using different models to estimate each ignores the dynamics of their joint determination. Finally, even where these problems do not arise, the models or the data used to estimate the unobserved parameters may simply be unsuitable for that purpose. ${ }^{1}$

An alternative, and more consistent, approach is to estimate $z$ within the model described by equation (1). That is, given data on actual market values for assets similar to the one of interest, we back out the value of $z$ implied by (1). This method is, of course, akin to that commonly employed in the field of option pricing to estimate stock price volatility. ${ }^{2}$ Valuing a stock option using standard pricing methods requires knowledge of the underlying stock volatility, which is unobservable. But reliable estimates can be obtained by inferring the volatility level that is consistent with (i.e., implied by) the observed market price of a similar option written on the same stock. This volatility estimate is then plugged back into the pricing formula in order to calculate the original option's value. Somewhat surprisingly, this approach has not previously been applied to the more general class of problems described above, perhaps because it is not immediately clear how, or whether, it can be easily extended to the situation where $z$ is a vector, i.e., when there are multiple unobserved parameters. Also, once one moves outside financial markets, it would be unusual to observe multiple claims and market prices for the same underlying asset.

In this paper, we show how the within-model approach can be generalized to accommodate these issues. Suppose first that there exist market data on sales of $n$ assets that are similar to the one that is the central object of study. For each such sale we observe the sales price $\left(V_{n}\right)$,

\footnotetext{
${ }^{1}$ For example, suppose the unobservable parameter is a risk-adjusted discount rate. Then an obvious approach is to use some theoretical model of risk adjustment such as the Capital Asset Pricing Model (CAPM). But the latter is strictly applicable only to the highly liquid assets traded in financial markets, and thus may provide highly biased estimates of discount rates for much less liquid assets such as land.

${ }^{2}$ For extensive reviews of this literature, see Corrado and Miller (1996) and Mayhew (1995).
} 
the policy parameter associated with that particular asset $\left(x_{n}\right)$, and the observable exogenous parameters $\left(y_{n}\right)$. We can then use this data to estimate the unobservable exogenous parameters $(z)$ using the regression equation

$$
V_{n}=f\left(F\left(x_{n}, y_{n}, z\right), \varepsilon_{n}\right), \quad n=1,2, \ldots, N
$$

for some function $f$ of the theoretical market value $F$ and a noise term $\varepsilon_{n}$. This form offers a variety of possibilities. For example, as we shall see below, one possibility is $f(V, \varepsilon)=V e^{\varepsilon}$, or equivalently

$$
\log V_{n}=\log F\left(x_{n}, y_{n}, z\right)+\varepsilon_{n} .
$$

Of course, as the function $F$ will typically be nonlinear, equation (2) is likely to be somewhat complex. But so long as the exact form of $F$ is known and the necessary data are available, this is easily accommodated by standard nonlinear regression methods. In this way, we can obtain internally consistent estimates of $z$ implied by a single valuation framework and thus avoid the need to utilise a variety of ad hoc methods and estimates.

In the remainder of the paper, we illustrate this approach using the concrete example of the rent-setting problem. In particular, we focus on the determination of equilibrium rental rates for ground leases of commercial land, as such transactions are economically significant and have received considerable recent attention in the literature (e.g., Dale-Johnson, 2001; Grenadier, 2005; Lally and Randal, 2004). The next section sets out a ground lease valuation model corresponding to equation (1), identifies the unobservable parameters, and shows how equation (2) can be used to estimate these. Section 3 applies this last step to some real-world data, while Section 4 offers some concluding remarks.

\section{Application: Ground Lease Rentals}

Ownership and use of long-lived assets such as land and infrastructure investments are often separated. Historically, land was provided as an endowment to institutions such as churches and universities, or to fund the development of railways, and the beneficiaries of those endowments then leased use of the land in perpetuity to maximise the rental income obtained from the endowment (Jackson, 1999). More recently investors have used long-term renewable leases to allow specialisation in the ownership and management of commercial real estate and infrastructure assets.

Long-term leases of unimproved land (commonly known as ground leases) normally provide for periodic reviews of the lease payments. In such reviews, the first step typically involves seeking agreement between the lessor and lessee, and where there is no agreement, through an arbitration process. Such leases have the following general characteristics:

1. Rental payments are due every $m$ years in advance and are fixed in nominal terms for $T$ years at which time they are reviewed. 
2. There are $n$ rent revisions scheduled during the life of the lease, i.e., the lease has a total length of $n T$ years.

3. The rent set at each review is based on the current market value of the land leased in an unimproved state, with no account taken of the value of the improvements affected by the lessee.

4. All expenses associated with the use of the property are payable by the lessee.

5. If the lease is forfeited or not renewed, all buildings and other improvements on the land revert to the lessor free from any payment or compensation.

6. The lessee may assign, sub-lease or sell his interest in the land with the consent of the lessor.

7. The lessor may assign or sell his interest in the land.

A crucial aspect of these leases, at both the date of inception and at subsequent review dates, is the setting of the rental payments to be made by the lessee. For the lease to be acceptable to both parties, the present value of these payments over the life of the lease must be equal to the market value of otherwise-equivalent unimproved freehold land. At a higher rental rate, the present value of rental payments is greater than the land value and the lessee would prefer to buy the land. At a lower rental rate, the present value of rental payments is less than the land value and the lessor would prefer to sell the land. From the financial economist's perspective, the interesting question is: what is the equilibrium rental rate? As a practical matter, this issue arises whenever the lessor and lessee are unable to agree. We now show how the approach described in the previous section can be used to shed light on this question.

\subsection{The valuation model}

The first step is to build a valuation model corresponding to the function $F$ in equation (1). Because estimation of (2) requires that the model be applicable to sales of leases occurring at any date during the rental cycle, we need to allow for the possibility that an arbitrary number

of years, $S$, has elapsed since the most recent review date. Suppose that similar unimproved land was determined to have value $L_{0}$ at the most recent review date and that an annual rental payment of $C$ was set; such land is now worth $L_{S}$.

When viewed from time $S$, the change in rent payments at the next review can be broken into two parts. First, unimproved land values have already grown by a factor of $L_{S} / L_{0}$ in the current cycle. Second, they are expected to grow by a factor of $e^{g(T-S)}$ over the remainder of the cycle, where $g$ is the continuously compounded expected annual growth rate in unimproved land value (which we assume to be constant). Thus, the expected annual rent payment during the next rent period equals

$$
C \cdot \frac{L_{S}}{L_{0}} \cdot e^{g(T-S)}
$$


The expected annual rent payment in the subsequent rent period equals

$$
C \cdot \frac{L_{S}}{L_{0}} \cdot e^{g(2 T-S)}
$$

where we have allowed for further growth of $e^{g T}$ in the land value. All subsequent expected rent payments can be calculated in the same way.

After allowing for tax and the fact that the next rent review is only $T-S$ years away, the present value of the rent payments received over the remainder of the current cycle is

$$
\left(1-t_{c}\right) m C\left(1+\frac{1}{e^{r m}}+\ldots+\frac{1}{e^{r(T-S-m)}}\right)=\left(1-t_{c}\right) m C \frac{1-e^{-r(T-S)}}{1-e^{-r m}},
$$

where $r$ denotes the risk-free interest rate and $t_{c}$ the tax rate. These payments are discounted at the risk-free interest rate because the rent payment only changes at the end of the current cycle, and so are risk-free within the current cycle. At the time of the next rent review (that is, at date $T$ ) the present value of the rent payments received over the subsequent cycle will equal

$$
\left(1-t_{c}\right) m C \frac{L_{T}}{L_{0}}\left(1+\frac{1}{e^{r m}}+\ldots+\frac{1}{e^{r(T-m)}}\right)=\left(1-t_{c}\right) m C \frac{L_{T}}{L_{0}} \frac{1-e^{-r T}}{1-e^{-r m}} .
$$

To calculate their present value at date $S$ we must discount the expected value of this expression back to date $S$ using the risk-adjusted discount rate appropriate for land-value risk, $k$. Thus, the date $S$ present value equals

$$
\left(1-t_{c}\right) m C \frac{L_{S}}{L_{0}} e^{(g-k)(T-S)} \frac{1-e^{-r T}}{1-e^{-r m}} .
$$

Post-tax cash flows received over future rent cycles can be valued in the same way.

Putting the pieces together shows that the market value of the lessor's interest in this lease is currently equal to

$$
\begin{aligned}
V_{S}= & \left(1-t_{c}\right) m C \frac{1-e^{-r(T-S)}}{1-e^{-r m}} \\
& +\left(1-t_{c}\right) m C \frac{L_{S}}{L_{0}} e^{(g-k)(T-S)} \frac{1-e^{-r T}}{1-e^{-r m}} \\
& +\left(1-t_{c}\right) m C \frac{L_{S}}{L_{0}} e^{(g-k)(2 T-S)} \frac{1-e^{-r T}}{1-e^{-r m}} \\
& +\ldots+\left(1-t_{c}\right) m C \frac{L_{S}}{L_{0}} e^{(g-k)((n-1) T-S)} \frac{1-e^{-r T}}{1-e^{-r m}} \\
& +L_{S} e^{(g-k)(n T-S)}
\end{aligned}
$$

where the final term is the expected (discounted) value of the land at the end of the lease. Simplifying the various geometric series appearing in this equation yields

$$
\begin{aligned}
V_{S}= & \left(1-t_{c}\right) m C\left(\frac{1-e^{-r(T-S)}}{1-e^{-r m}}\right) \\
& +\left(1-t_{c}\right) m C \frac{L_{S}}{L_{0}} e^{(g-k)(T-S)}\left(\frac{1-e^{-r T}}{1-e^{-r m}}\right) \frac{1-e^{(g-k)(n-1) T}}{1-e^{(g-k) T}} \\
& +L_{S} e^{(g-k)(n T-S)} .
\end{aligned}
$$


This is our valuation model. Relating it back to equation (1), the policy parameter $x$ is the rental payment $C$, the observable exogenous parameters are $y=\left(m, n, S, T, t_{c}, L_{0}, L_{S}, r\right)$, and the unobservable exogenous parameters are $z=(g, k)$.

\subsection{Setting the policy parameter}

Given estimates of $g$ and $k$, we can use the valuation model (3) to determine the equilibrium rental payment $C$. Since this is set at the time of a rent review (when $S=0$ and $L_{S}=L_{0}$ ), we use the corresponding special case of $(3):^{3}$

$$
V_{0}=\left(1-t_{c}\right) m C\left(\frac{1-e^{-r T}}{1-e^{-r m}}\right) \frac{1-e^{(g-k) n T}}{1-e^{(g-k) T}}+L_{0} e^{(g-k) n T} .
$$

The rental payment $C$ that makes this equal to the land value is the level of $C$ such that

$$
L_{0}=\left(1-t_{c}\right) m C\left(\frac{1-e^{-r T}}{1-e^{-r m}}\right) \frac{1-e^{(g-k) n T}}{1-e^{(g-k) T}}+L_{0} e^{(g-k) n T} .
$$

Solving this equation for $C$ yields

$$
C=\frac{1-e^{-(k-g) T}}{\left(1-t_{c}\right) m}\left(\frac{1-e^{-r m}}{1-e^{-r T}}\right) L_{0} .
$$

Clearly, implementation of equation (4) requires us to estimate the unobservable exogenous parameters $g$ and $k$. Note, however, that $C$ does not depend on the individual values of $g$ and $k$, but only on their relative value, as indicated by the term $\phi=k-g$. If $\phi$ is high, then the proportion of total return offered by expected capital gain is low, and hence the required rental rate is high; if $\phi$ is low, then the proportion of total return offered by expected capital gain is high, and hence the required rental rate is low. As a result, alternative combinations of $g$ and $k$ that yield the same value of $\phi$ have no effect on $C$.

One way of implementing equation (4) is to estimate $g$ and $k$ using additional external models. For example, the CAPM could be used to calculate $k$ while $g$ could be estimated as the average annual growth rate in historical land price data. However, as discussed in section 1 , this approach has significant disadvantages. ${ }^{4}$ Instead, as we now show, a simpler method that requires only the original valuation model is possible.

\footnotetext{
${ }^{3}$ Lally (2001) and Lally and Randal (2004) use the discrete-compounding version of this equation in their analyses of the rent-setting problem.

${ }^{4}$ In particular, financial market models such as the CAPM assumes that all assets are freely marketable, perfectly divisible, and highly liquid. Although such assumptions are perfectly reasonable for most financial markets, they are not a very good description of land markets. Sales of land are often time consuming, while marketing of the land and transfer of title are both costly. Land is also a lumpy asset: the need to create complex covenants to facilitate capital intensive use of a site with multiple owners, as well as regulatory/planning restrictions on minimum lot size, mean that it is not easily divisible into small units to facilitate individual title to many owners. As a result, the CAPM is likely to significantly understate $k$ because it makes no allowance for the risks associated with poor liquidity. Many studies in finance (e.g., Silber, 1991; Longstaff, 1995; Acharya and Pedersen, 2005) suggest that investors rationally require a higher rate of return to invest in illiquid assets such as land, and that this premium can be large.
} 


\subsection{Estimating the unobservable parameters}

Suppose there exist market data on secondary market transactions in ground lease rentals, i.e., where the lessor sells his interest in a ground lease to a third party (who could potentially be the lessee). The asset traded in such transactions offers (i) the right to receive rental payments during the remaining term of the lease and (ii) the right to the land at the termination of the lease. Thus, the equilibrium price $P_{S}$ of a sale that occurs $S$ years into a lease must be equal to the present value of the remaining rental payments plus the residual land value at the end of the lease, which is the expression in (3). We can rewrite this as

$$
P_{S}-\left(1-t_{c}\right) m C\left(\frac{1-e^{-r(T-S)}}{1-e^{-r m}}\right)=\left(\frac{L_{S}}{L_{0}}\right) A,
$$

where

$$
A=\left(1-t_{c}\right) m C e^{(g-k)(T-S)}\left(\frac{1-e^{-r T}}{1-e^{-r m}}\right) \frac{1-e^{(g-k)(n-1) T}}{1-e^{(g-k) T}}+L_{0} e^{(g-k)(n T-S)}
$$

Assuming that the rental payment for this lease was set consistent with (4), the expression for $A$ reduces to

$$
A=\left(\frac{1-e^{-r T}}{1-e^{-r m}}\right)\left(\frac{\left(1-t_{c}\right) m C}{1-e^{(g-k) T}}\right) e^{(g-k)(T-S)}
$$

We can therefore rewrite equation (5) as

$$
Q_{S}=\left(\frac{e^{(g-k)(T-S)}}{1-e^{(g-k) T}}\right)\left(\frac{L_{S}}{L_{0}}\right)
$$

where

$$
Q_{S}=\frac{P_{S}}{\left(1-t_{c}\right) m C}\left(\frac{1-e^{-r m}}{1-e^{-r T}}\right)-\left(\frac{1-e^{-r(T-S)}}{1-e^{-r T}}\right)
$$

is a linear transformation of the lease's price-earnings ratio. ${ }^{5}$ Note that all components of $Q_{S}$ are observable, so for any given realisation of $L_{S} / L_{0}$ there is a unique value of $\phi$ that satisfies equation (6).

To close the model, we therefore need some assumption about the distribution of the unimproved land growth factor $L_{S} / L_{0}$. We suppose that $L_{S}$ follows a geometric Brownian motion with volatility $\sigma$ and drift $g .{ }^{6}$ That is

$$
L_{S}=L_{0} \exp \left(\left(g-\frac{\sigma^{2}}{2}\right) S+\varepsilon_{S}\right), \quad \varepsilon_{S} \sim N\left(0, \sigma^{2} S\right),
$$

Taking the natural logarithm of each side of (6), using the above process for $L_{S}$, and splitting $k$ into a risk-free component $(r)$ and a time-invariant risk premium $(\lambda)$, yields

$$
\log Q_{S}=S\left(r+\lambda-\frac{\sigma^{2}}{2}\right)-\log \left(e^{(r+\lambda-g) T}-1\right)+\varepsilon_{S},
$$

\footnotetext{
${ }^{5}$ For a lease with a one-year term $(T=1)$ and annual rent payments $(m=1)$ that is sold on a rent-setting date $(S=0), Q_{S}=P_{S} /\left(\left(1-t_{c}\right) C\right)-1$.

${ }^{6}$ Note that this assumption implies $E_{0}\left[L_{S}\right]=e^{g S} L_{0}$, consistent with our earlier assumption that unimproved land value is expected to grow at a constant rate $g$.
} 
which is readily recognisable as a standard regression model with heteroskedastic disturbances and unknown parameters $g, \lambda$, and $\sigma$. Although this model is nonlinear, it is straightforward to obtain maximum likelihood estimates of these parameters from market data, which can then be used in equation (4) to arrive at a value for $C .^{7}$ Overall, only the ground lease valuation model and data on sales of ground leases are required. ${ }^{8}$

One cautionary note is in order. Although the within-model approach described by equations (3)-(7) provides a simple and internally-consistent method for estimating a ground lease rental rate, it is crucially dependent on the assumption that market prices for lease sales are reliable indicators of value, i.e., that the secondary market for ground leases is in some sense 'efficient'. In this context, one potential problem is the presence of 'fire sales' - leases that are sold for an artificially low price due to financial distress on the part of the original lessor. If such transactions were prevalent in the data used to estimate (7), then the estimated value of $\lambda-$ and hence $C$ - would tend to be biased upwards. However, $(7)$ is only defined when $Q_{S}>0$; that is, when

$$
\frac{P_{S}}{\left(1-t_{c}\right) C}>m\left(\frac{1-e^{-r(T-S)}}{1-e^{-r m}}\right),
$$

where the right-hand term is approximately equal to $T-S$. Consequently, equation (7) can only be estimated when the sale price exceeds total rent payments remaining in the current cycle, which automatically rules out transactions with obvious fire sales qualities.

\section{Example}

To illustrate the approach described in Section 2.3, we consider a lease that requires rent to be paid annually $(m=1)$, set the tax rate equal to 0.33 , the current risk-free interest rate $r^{\prime}$ to 0.045 (i.e., the rate prevailing on the rent-setting day for the lease whose equilibrium rental rate we wish to determine), and use data from 30 ground lease sales that occurred in the Wellington region of New Zealand between April 1993 and March 2007..$^{9}$ The details of these transactions are listed in Table 1. As a proxy for $r$, we use the 5-year government bond rate prevailing on the date that the sale occurred.

Estimating equation (7) using the Table 1 data yields the results appearing in Table $2 .{ }^{10}$

\footnotetext{
${ }^{7}$ In applying this procedure, $g, \lambda$, and $\sigma$ are chosen to minimize the weighted sum of squared errors, where the weight allocated to each data point is the reciprocal of the number of years between the sale and the most recent revision. It follows that sales that occur a long time into a lease cycle have a relatively low influence on parameter estimates.

${ }^{8}$ Note also that if the lease under consideration has a so-called ratchet clause (whereby rents can never fall from one period to the next) that necessitates the use of option pricing methods, our approach's estimate of $\sigma$ eliminates the need to undertake a separate estimation of land value volatility.

${ }^{9}$ We are grateful to Wareham Cameron Ltd for providing this information. One further transaction was deleted from the sample because it failed to pass the fire sale test described above.

${ }^{10}$ Because information on the frequency of rent payments is unavailable, we assume that all leases in Table 2 make annual payments. We also assume $t_{c}=0.33$, the statutory corporate tax rate in New Zealand throughout
} 
Table 1: Data on Ground Lease Sales

This table summarises data from 30 ground lease sales that occurred in the Wellington region between April 1993 and March 2007. $T$ is the term of the lease in years, $S$ is the number of years between the date on which the sale occurred and the previous rent review date, $C$ is the annual rent payment on the lease as set at the last review date, $P$ is the price at which the lease was sold, and $r$ is the after-tax 5-year government bond rate prevailing on the date that the sale occurred.

\begin{tabular}{rrrrrc}
\hline SOLI & \multicolumn{1}{c}{$T$} & \multicolumn{1}{c}{$S$} & \multicolumn{1}{c}{$C$} & \multicolumn{1}{c}{$P$} & $r$ \\
\hline 1 & 21.083 & 0.764 & 35438 & 390000 & 0.042 \\
2 & 14.075 & 0.833 & 149688 & 1855000 & 0.049 \\
3 & 5.000 & 0.833 & 60000 & 640000 & 0.039 \\
4 & 13.997 & 0.842 & 87857 & 850000 & 0.047 \\
5 & 5.000 & 0.917 & 6977 & 110000 & 0.049 \\
6 & 7.000 & 1.303 & 100000 & 920000 & 0.057 \\
7 & 14.000 & 1.314 & 59500 & 740000 & 0.039 \\
8 & 5.000 & 1.750 & 24464 & 330000 & 0.048 \\
9 & 2.964 & 1.881 & 90000 & 800000 & 0.048 \\
10 & 5.000 & 2.167 & 39000 & 420000 & 0.058 \\
11 & 5.000 & 2.250 & 5450 & 62500 & 0.052 \\
12 & 12.000 & 2.333 & 315000 & 3302500 & 0.057 \\
13 & 21.000 & 2.400 & 24625 & 352000 & 0.044 \\
14 & 21.000 & 2.917 & 172500 & 2350000 & 0.038 \\
15 & 7.000 & 3.333 & 28125 & 354000 & 0.057 \\
16 & 21.000 & 3.583 & 12378 & 165000 & 0.048 \\
17 & 5.000 & 4.167 & 516250 & 9831375 & 0.043 \\
18 & 5.000 & 4.167 & 225060 & 4083750 & 0.043 \\
19 & 5.083 & 4.917 & 13500 & 235000 & 0.056 \\
20 & 7.000 & 4.919 & 15148 & 168000 & 0.040 \\
21 & 7.000 & 5.667 & 47303 & 525583 & 0.046 \\
22 & 21.000 & 8.658 & 41915 & 450000 & 0.057 \\
23 & 12.000 & 8.917 & 122000 & 2000000 & 0.039 \\
24 & 21.000 & 9.333 & 550400 & 5181500 & 0.047 \\
25 & 21.000 & 9.917 & 76000 & 875000 & 0.039 \\
26 & 20.000 & 10.333 & 6175 & 65000 & 0.039 \\
27 & 21.000 & 12.000 & 514528 & 4100000 & 0.039 \\
28 & 13.997 & 12.342 & 87857 & 6700000 & 0.040 \\
29 & 21.000 & 15.083 & 51800 & 550000 & 0.044 \\
30 & 21.083 & 18.667 & 30987 & 750000 & 0.040 \\
\hline & & & & &
\end{tabular}

The first three columns show the maximum likelihood estimates of the long-run expected growth rate in the value of unimproved land $(\hat{g})$, the risk premium component of the expected return on such land $(\hat{\lambda})$, and the volatility in the growth of land value $(\hat{\sigma})$; asymptotic standard errors for these estimates are given in parentheses. The fourth column shows the resulting estimate of $\phi=r^{\prime}+\lambda-g$. The final three columns then use equation (4) to estimate the rental rate $\hat{R}=C / L_{0}$ for this lease, assuming lease terms of 5, 10 and 21 years respectively. We use the delta method (see Greene, 2003; and Xu and Long, 2005) to obtain standard errors for $\hat{\phi}$ and $\hat{R}$.

We first check the model specification: if correctly specified, then the standardized residuals (i.e., the residual for each sale divided by $\sqrt{S}$ ) should be normally distributed. The Bera-Jarque the period covered by our data. 
Table 2: Maximum likelihood estimates of equation (7) using data on ground lease sales

Assuming a lease with annual rent payments $(m=1.0)$ and a current risk-free interest rate of $4.5 \%$ $\left(r^{\prime}=0.045\right)$, this table uses the data in Table 1 to obtain maximum-likelihood estimates of $g, \lambda$, and $\sigma$ from equation (7). These are in turn used to obtain estimates of, firstly, $\phi=r+\lambda-g$, and then, from equation (4), the rental rate $R$ for varying length of lease. Asymptotic standard errors are in parentheses; for $\hat{\phi}$ and $\hat{r}$, these are calculated using the delta method. The second and third panels repeat this exercise for ground lease sales where the purchaser is an outside investor and the lessee respectively.

\begin{tabular}{lccccccc}
\hline Sample & $\hat{g}$ & $\hat{\lambda}$ & $\hat{\sigma}$ & $r+\hat{\lambda}-\hat{g}$ & \multicolumn{3}{c}{$\hat{R}$} \\
& & & & & $T=5$ & $T=10$ & $T=21$ \\
\hline Full $(n=30)$ & 0.078 & 0.106 & 0.266 & 0.073 & 0.100 & 0.094 & 0.084 \\
& $(0.027)$ & $(0.030)$ & $(0.034)$ & $(0.005)$ & $(0.006)$ & $(0.004)$ & $(0.002)$ \\
\hline Sales to outside & 0.075 & 0.104 & 0.234 & 0.074 & 0.101 & 0.095 & 0.085 \\
$\quad$ investors $(n=12)$ & $(0.039)$ & $(0.043)$ & $(0.048)$ & $(0.006)$ & $(0.007)$ & $(0.005)$ & $(0.003)$ \\
\hline Sales to the & 0.080 & 0.107 & 0.285 & 0.072 & 0.099 & 0.093 & 0.084 \\
$\quad$ lessee $(n=18)$ & $(0.037)$ & $(0.042)$ & $(0.047)$ & $(0.007)$ & $(0.008)$ & $(0.006)$ & $(0.004)$ \\
\hline
\end{tabular}

test statistic for normality of the adjusted residuals equals 0.170 . Since the test statistic is asymptotically distributed according to $\chi_{[2]}^{2}$, implying a $p$-value of 0.919 , we cannot reject the null hypothesis that the residuals are normally distributed at conventional levels of significance.

Turning to the Table 2 parameter estimates, we see that $\hat{g}=0.078, \hat{\lambda}=0.106$, and $\hat{\sigma}=0.266$. Together, these estimates imply $\hat{\phi}=0.073$ and, for a 10 -year lease, $\hat{R}=9.4 \%$. The corresponding rental rates for 5- and 21-year leases are $10.0 \%$ and $8.4 \%$ respectively. Overall, the equilibrium rental rate lies approximately halfway between the implied expected return on unimproved land $(4.5 \%+10.6 \%=15.1 \%)$ and the risk-free interest rate of $4.5 \%$, reflecting the fact that the lease payments are certain between rent reviews but are subject to the risk of changes in land value at the review dates.

These results have two features of particular interest. First, the implied $10.6 \%$ risk premium for unimproved land is consistent with other risk premium estimates for illiquid assets - see, for example, Kerins et al. (2004) and Acharya and Pedersen (2005). Thus, our within-model approach appears to adequately capture liquidity risks. Second, $\phi$ is very precisely estimated even though $g$ and $\lambda$, are not. This can be seen more clearly in Figure 1 which plots the 'confidence ellipse' for the latter two parameter estimates. For any combination of $g$ and $\lambda$ inside the region bounded by the solid curve, we cannot reject the null hypothesis (at a $5 \%$ level) that the parameters take these values. However, we can reject this hypothesis for any combination outside the region bounded by the solid curve. The narrow shape of the ellipse indicates that the estimates of $g$ and $\lambda$ are highly positively correlated, the source of which is apparent from equation (6). Other than via the $L_{S}$ term, $P_{S}$ depends only on $\phi$ and not on the individual values of $g$ and $\lambda$, so the regression model - equation (7) - is close to being underidentified. As a result of this property, any estimation error in $\hat{g}$ (which affects the numerator of 
Figure 1: Confidence ellipse for average growth rate and risk premium

The point in the middle of the graph shows the point estimate of $g$ and $\lambda$, while the two sets of dashed lines show the $95 \%$ confidence intervals for each parameter separately. For any combination of $g$ and $\lambda$ inside the region bounded by the solid curve, we cannot reject the null hypothesis (at a $5 \%$ level) that the parameters take these values. However, we can reject this hypothesis for any combination outside the region bounded by the solid curve.

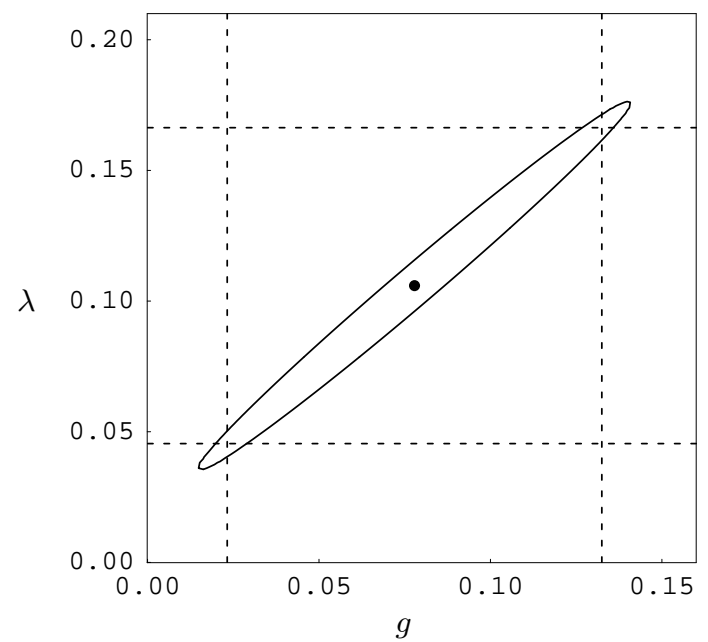

$\phi$ ) will tend to be substantially offset by an estimation error in $\hat{\lambda}$ (which affects the denominator of $\phi$ ). Consequently, although the components of $\phi$ have relatively substantial estimation errors, $\phi$ itself does not. And since the rental rate is a function of $\phi$ only (and not $g$ and $\lambda$ separately), the precision in estimating $\phi$ feeds through into the estimated rental rates. For example, the lease with ten-yearly rent reviews $(T=10)$ has an estimated rental rate of $9.4 \%$ with a $95 \%$ confidence interval of $[0.086,0.102]$.

Our sales data sample contains two types of transactions: those where the lease is sold to an outside investor and those where it is sold to the lessee. In case the dynamics underlying these two cases differ, we repeat our estimation exercise for each group separately. Although, as can be seen in the second and third panels of Table 2, this results in slightly higher standard errors due to the smaller number of observations, it has no meaningful effect on the rental rate point estimates: regardless of the type of transaction, the estimated rental rate is essentially identical to that obtained for the full sample.

\section{Concluding Remarks}

Disputes over inter-party payments relating to asset ownership or assignment frequently arise. Financial economists can often provide apparent solutions to such debates via analytical models that offer a simple formula for the variable in dispute. However, such formulae invariably contain unobservable parameters that themselves become the focus of dispute. 
A common approach to estimating these parameters consists of applying historical data to additional analytical models that describe the determination of the relevant parameters. However, the problems associated with this approach can lead to significant errors. In this paper, we have described an alternative within-model approach that involves only the application of the original analytical framework to actual market transactions in the asset that is the subject of dispute. This approach has the singularly attractive feature that all unknown parameters (including the policy, or disputed, parameter) are calculated within a single valuation framework, thus avoiding the need to appeal to additional models that may or may not be consistent with the original model, or to use data that may or may not be relevant to the asset of interest.

Applying the within-model approach to the determination of ground lease rental rates, we have, first, developed a simple model of rent determination, and then, in conjunction with data on ground lease sales, used this model to estimate both the unobservable parameters on which the rental rate depends and the rental rate itself. All estimates obtained in this way appear to be economically plausible, despite our data sample being quite small. In general, our approach can be used wherever an appropriate asset valuation model is available and there are sufficient secondary market transactions to provide a viable data set.

\section{References}

Acharya, V. and L. Pedersen, 2005. Asset pricing with liquidity risk. Journal of Financial Economics 77, 375-410.

Corrado, C. and T. Miller, 1996. Efficient option-implied volatility estimators. Journal of Futures Markets 16, 247-272.

Dale-Johnson, D. 2001. Long-term ground leases, the redevelopment option and contract incentives. Real Estate Economics 29, 451-484.

Greene, W. 2003. Econometric Analysis, 5th Ed. New York: Prentice-Hall.

Grenadier, S., 2005. An equilibrium analysis of real estate leases. Journal of Business 78, 1173-1214.

Jackson, M, 1999. An inquiry into the origins of the Glasgow Lease. New Zealand Valuers Journal March, 48-58.

Kerins, F., J. Smith and R. Smith, 2004. Opportunity cost of capital for venture capital investors and entrepreneurs. Journal of Financial and Quantitative Analysis 39, 385-405.

Lally, M., 2001. The rental rate on land, revision frequency and inflation. Pacific Accounting Review 13, 17-34. 
Lally, M. and J. Randal, 2004. Ground rental rates and ratchet clauses. Accounting and Finance 44, 187-202.

Longstaff, F., 1995. How much can marketability affect security values? Journal of Finance 50, $1767-1774$.

Mayhew, S., 1995. Implied volatility. Financial Analysts Journal 51, 8-20

Silber, W., 1991. Discounts on restricted stock: The impact of illiquidity on stock prices. Financial Analysts Journal 47, 60-64.

$\mathrm{Xu}, \mathrm{J}$. and J. Long, 2005. Confidence intervals for predicted outcomes in regression models for categorical outcomes. Stata Journal 5, 537-559. 